\title{
Clinical profile and outcome of COVID positive obstetric patients in a tertiary care hospital: a retrospective study
}

\author{
Asma Hassan Mufti ${ }^{1}$, Samar Mukhtar ${ }^{1}$, Mehmood-Ul-Hassan Mufti², Nasir Jeelani Wani*
}

${ }^{1}$ Department of Obstetrics and Gynecology, ${ }^{2}$ Department of Orthopedics, ${ }^{3}$ Department of Anaesthesia and Critical Care, Government Medical College, Srinagar, Jammu and Kashmir, India

Received: 24 July 2021

Accepted: 16 August 2021

\section{*Correspondence:}

Dr. Nasir Jeelani Wani,

E-mail: Nasirjw@gmail.com

Copyright: ( $)$ the author(s), publisher and licensee Medip Academy. This is an open-access article distributed under the terms of the Creative Commons Attribution Non-Commercial License, which permits unrestricted non-commercial use, distribution, and reproduction in any medium, provided the original work is properly cited.

\section{ABSTRACT}

Background: To study clinical profile, maternal and fetal outcome in COVID positive pregnancies.

Methods: A retrospective observational study was done at Lalla ded hospital, Kashmir, a tertiary care centre. 70 COVID positive pregnant women who were admitted from May 2020 to January 2021 were included in the study.

Results: The incidence of COVID positive patients in our study was $11.47 \% .60 \%$ of patients in our study belonged to 26-30 years age group. $50 \%$ patients were primigravida, $20 \%$ were second gravid. Among the study population, 31 $(44.3 \%)$ patients were term while $22(31.4 \%)$ were preterm. Most patients were asymptomatic (61.4\%). Among symptomatic patients, maximum had fever (17.1\%) followed by cough $(10 \%)$ and shortness of breath $(4.3 \%)$. Associated comorbidity was seen in 33 patients (47.1\%). Hypertensive disorders of pregnancy were seen in majority i.e. $15.7 \%$, followed by anaemia (11.4\%), GDM (8.5\%) and hypothyroidism $(7.1 \%)$. Out of total study population of 70, emergency cesarean delivery (LSCS) was done in 29 patients $(41.5 \%) .21$ patients delivered vaginally $(30 \%)$. Two post-LSCS patients were shifted to designated COVID Intensive care unit (ICU). One patient from the study group died. There were total of 50 deliveries, 10 babies had Neonatal ICU admission (20\%), Low birth weight in 9 (18\%). Low APGAR score was in $6(12 \%)$. There were 2 stillbirths in the study population.

Conclusions: COVID presents as milder disease in pregnancy, but it may be severe in those with associated comorbidities. More studies on susceptibility of pregnant women to infection by COVID-19 are required.

Keywords: COVID-19, Maternal outcome, Fetal outcome

\section{INTRODUCTION}

Corona viruses are a group of single stranded RNA, nonsegmented, enveloped viruses that can cause illness in humans and animals. Novel CoV (SARS-CoV-2) is a newly discovered strain of coronavirus causing covid-19. Other human coronavirus infections cause mild to moderate upper respiratory illness like common cold, Middle East respiratory syndrome (MERS-CoV) and severe acute respiratory syndrome (SARS-CoV). ${ }^{1}$ Outbreak of COVID-19 was first noticed in a seafood market in Wuhan city in Hubei province of China in December 2019 and has now spread worldwide, leading to an ongoing pandemic. ${ }^{2}$ WHO declared it as the $6^{\text {th }}$ public health emergency of international concern on $30^{\text {th }}$ January 2020. Subsequently, WHO declared COVID-19 as a pandemic on $11^{\text {th }}$ march $2020 . .^{3}$ Most global cases of COVID-19 have evidence of human to human transmission, known to occur most often through close contact with an infected person (within 2 meters) or from contaminated surfaces. The incubation period varies from 2 days to 2 weeks following exposure to the virus. ${ }^{4}$ COVID-19 is still an emerging and actively spreading disease worldwide. An important population that deserves meticulous consideration during the COVID-19 pandemic is the pregnant. 
Pregnant women do not appear more likely to contract infection than general population. ${ }^{5-7}$ Most pregnant women will experience only mild to moderate cold or flu. Cough, fever, shortness of breath, running nose, headaches and anosmia are other relevant symptoms. ${ }^{8}$ Pregnancy is regarded as an immune compromised state in some aspects, especially since maternal immunity is altered to tolerate fetal antigens by suppressing cellmediated immunity. ${ }^{9}$ A whole cluster of systemic effects which propagate the risk of complications from respiratory infections arise due to altered physiological and immunological state that is typical component of pregnancy. The cardiovascular and respiratory component of these changes along with development of an immunological adaptation that allows the maternal body to tolerate antigenically diverse fetus, inflate the risk toward development of severe respiratory disease. ${ }^{10}$ The changes in the immune system of pregnant women make them more susceptible to infectious processes, in addition to the manifestations of the infection, with the risk of adverse maternal and neonatal complications, premature birth, spontaneous abortion, application of endotracheal intubation, restriction of intrauterine growth, hospitalization in an intensive care unit, renal failure, intravascular coagulopathy, and transmission to the fetus or newborn. ${ }^{11}$ To date, there is no conclusive evidence of vertical transmission of Covid-19.12,13 Although transmission of virus to fetus or baby during delivery or pregnancy has not been proven, presence of antibodies has already been identified namely specific $\mathrm{IgG}$ for viruses in neonatal serum samples. ${ }^{14}$ Current studies on the susceptibility of pregnant women to infection by COVID-19 are still incipient. This study aims to add to the limited knowledge we have with regards to COVID-19 infection and pregnancy.

\section{METHODS}

A retrospective, observational study was conducted in the Lalladed hospital which is a tertiary care hospital of Kashmir, India from May 2020 to January 2021. All pregnant women who were admitted in this hospital during the study period and who turned out COVID positive by RT-PCR test irrespective of their period of gestation were included in the study. An isolation facility, separate from the main hospital had been set up to cater to the COVID positive pregnant women amid the ongoing pandemic. A total of 610 patients who were suspected to have COVID-19 presented to the isolation facility. Out of these, 70 patients were COVID positive by RT-PCR test and were included in this study. Various clinico-epidemological parameters, maternal and fetal outcome were thoroughly studied among the selected patients.

\section{RESULTS}

In our study 610 pregnant patients presented to isolation facility who were suspected to have COVID infection during the study period. Among these, total admitted pregnant women who came out to be COVID positive by RT-PCR were 70. So the incidence of COVID positive patients in our study was $11.47 \%$.

Table 1: Age distribution.

\begin{tabular}{|lll|}
\hline Age (years) & $\mathbf{N}$ & $\%$ \\
\hline $\mathbf{2 0 - 2 5}$ & 7 & 10 \\
\hline $\mathbf{2 6 - 3 0}$ & 42 & 60 \\
\hline $\mathbf{3 1 - 3 5}$ & 17 & 24.3 \\
\hline Above 35 & 4 & 5.7 \\
\hline
\end{tabular}

Table 2: Parity.

\begin{tabular}{|lll|}
\hline Parity & N & $\%$ \\
\hline Primigravida & 35 & 50 \\
\hline G2 & 14 & 20 \\
\hline G3 and above & 21 & 30 \\
\hline
\end{tabular}

Table 3: Residence.

\begin{tabular}{|lll|}
\hline Residence & N & $\%$ \\
\hline Urban & 15 & 21.4 \\
\hline Rural & 55 & 78.6 \\
\hline
\end{tabular}

Table 4: Period of gestation.

\begin{tabular}{|lll|}
\hline Period of gestation & N & $\%$ \\
\hline Before viability & 9 & 12.9 \\
\hline Preterm & 22 & 31.4 \\
\hline Term & 31 & 44.3 \\
\hline Post-dated & 8 & 11.4 \\
\hline
\end{tabular}

Majority of patients in our study belonged to 26-30 years age group i.e. $60 \%$. This was followed by $31-35$ years age group which made $24.3 \%$ of all the study population. In our study, $50 \%$ patients were primigravida, $20 \%$ were second gravida. Rest were third gravida and above. Majority of our study population was rural i.e.78.6\%. Among the study population, 31(44.3\%) patients were term while $22(31.4 \%)$ were preterm. $9(12.9 \%)$ presented before age of viability while as $8(11.4 \%)$ were postdated. Most patients were asymptomatic (61.4\%) and had no symptom specific of COVID-19. Among symptomatic patients maximum had fever $(17.1 \%)$, followed by cough $(10 \%)$ and shortness of breath $(4.3 \%)$. Other relevant symptoms were chills, headache and running nose. Majority of patients who had no COVID specific symptoms, came with labour pains (32.6\%). This was followed by decreased perception of fetal movements (23.3\%), leaking per vaginum $(18.7 \%)$ and bleeding per vaginum (13.9\%). Two patients (4.6\%) had USG documented ruptured ectopic while three (6.9\%) had missed abortion.

Associated comorbidity was seen in 33 patients (47.1\%) among the study population. Hypertensive disorders of pregnancy were seen in majority i.e. $15.7 \%$, followed by 
anaemia (11.4\%), GDM $(8.5 \%)$ and hypothyroidism (7.1\%). Asthma was found in 2 patients $(2.8 \%)$ and 1 patient had history of anti-tubercular therapy intake. Out of total study population of 70, emergency cesarean delivery (LSCS) was done in 29 patients $(41.5 \%)$. LSCS was done for obstetric indications, most common being acute fetal distress. 21 patients delivered vaginally (30\%). Thus incidence of LSCS was more than vaginal delivery in our study. Hysterotomy was done in 1 patient for chorioamnionitis. 3 patients underwent dilatation and curettage for missed abortion. Emergency laparotomy was done in 2 patients for ruptured ectopic. Eleven patients, who were remote from term, were managed conservatively according to laid guidelines.

Table 5: Presenting symptoms.

\begin{tabular}{|lll|}
\hline Presenting symptoms & $\mathbf{N}$ & $\%$ \\
\hline $\begin{array}{l}\text { Asymptomatic but with obstetric } \\
\text { complaints }\end{array}$ & 43 & 61.4 \\
\hline Fever & 12 & 17.1 \\
\hline Shortness of breath & 3 & 4.3 \\
\hline Cough & 7 & 10 \\
\hline Chills & 2 & 2.9 \\
\hline Headache & 2 & 2.9 \\
\hline Rhinorrhea & 1 & 1.4 \\
\hline
\end{tabular}

Table 6: Obstetric complaints in asymptomatic.

\begin{tabular}{|lll|}
\hline Obstetric complaints & $\mathbf{N}$ & $\%$ \\
\hline Bleeding per vaginum & 6 & 13.9 \\
\hline Leaking per vaginum & 8 & 18.7 \\
\hline Decreased fetal movements & 10 & 23.3 \\
\hline Labour pains & 14 & 32.6 \\
\hline $\begin{array}{l}\text { USG documented ruptured } \\
\text { ectopic pregnancy }\end{array}$ & 2 & 4.6 \\
\hline Missed abortion & 3 & 6.9 \\
\hline
\end{tabular}

Table 7: Associated comorbidity.

\begin{tabular}{|lll|}
\hline Associated condition & $\mathrm{N}$ & $\%$ \\
\hline $\begin{array}{l}\text { Hypertension/pregnancy induced } \\
\text { hypertension }\end{array}$ & 11 & 15.7 \\
\hline $\begin{array}{l}\text { Gestational diabetes mellitus/ } \\
\text { diabetes mellitus }\end{array}$ & 6 & 8.5 \\
\hline Anaemia & 8 & 11.4 \\
\hline Asthma & 2 & 2.8 \\
\hline Hypothyroidism & 5 & 7.1 \\
\hline $\begin{array}{l}\text { History of anti-tubercular } \\
\text { therapy intake }\end{array}$ & 1 & 1.4 \\
\hline Total & 33 & 47.1 \\
\hline
\end{tabular}

Two post-LSCS patients who required advanced ionotropic support and critical care were shifted to designated COVID Intensive care unit (ICU). There was one death during the whole study period. The said patient was COVID positive with provisional diagnosis of severe pre eclampsia with pulmonary edema. During the study period, there were total of 50 deliveries which included both cesarean and vaginal deliveries. Among them 10 babies required neonatal ICU admission (20\%). Low birth weight was seen in $9(18 \%)$. Low APGAR score was found in $6(12 \%)$. There were 2 stillbirths which comprised $4 \%$ of total births in the study population.

Table 8: Maternal outcome.

\begin{tabular}{|lll|}
\hline Outcome & N & $\%$ \\
\hline Emergency cesarean delivery & 29 & 41.5 \\
\hline Vaginal delivery & 21 & 30 \\
\hline Dilatation and curettage & 3 & 4.2 \\
\hline Hysterotomy & 1 & 1.4 \\
\hline Emergency laparotomy & 2 & 2.8 \\
\hline Conservative management & 11 & 15.9 \\
\hline $\begin{array}{l}\text { Shifted to COVID intensive care } \\
\text { unit }\end{array}$ & 2 & 2.8 \\
\hline Death & 1 & 1.4 \\
\hline
\end{tabular}

Table 9: Fetal outcome.

\begin{tabular}{|lll|}
\hline Fetal outcome & N & $\%$ \\
\hline Birth weight $<\mathbf{2 5 0 0 g}$ & 9 & 18 \\
\hline APGAR score $<7$ at 0 min & 6 & 12 \\
\hline Neonatal ICU admission & 10 & 20 \\
\hline Stillbirth & 2 & 4 \\
\hline
\end{tabular}

\section{DISCUSSION}

COVID-19 is a new and emerging disease, caused by a novel coronavirus that has not previously been seen in humans. The COVID-19 pandemic has been the biggest global public health crisis in this century. Pregnancy is a state that is particularly susceptible to infectious diseases, and it is unsurprising that viral infections may affect pregnancy outcomes; previous literature has revealed that viral respiratory illnesses may lead to a higher risk of obstetric complications and adverse perinatal outcome, primarily due to changes in the immune response. ${ }^{14-16}$ But the course of the disease has been found to be milder in pregnant women in most case series from across the globe. ${ }^{17}$

This study was a retrospective observational study in which 70 COVID positive pregnancies were studied in terms of various clinicodemographic factors, maternal as well as fetal outcomes. The incidence of COVID positive patients in our study was $11.47 \%$. Majority of patients in our study belonged to $26-30$ years age group i.e. $60 \%$. In a study done by Vivanti et al mean age of COVID positive pregnant patients was 33.7 years while as in other study done by Yan et al mean age was 30. 3 years. $^{18,19}$ Most of the patients i.e. $50 \%$ were primigravida. Among the study population, 31 (44.3\%) patients were term while $22(31.4 \%)$ were preterm. Among symptomatic patients maximum had fever $(17.1 \%)$, followed by cough $(10 \%)$ and shortness of breath $(4.3 \%)$. In a study of pregnant women by Jeong et 
al the proportions were $28 \%, 51 \%$, and $21 \%$, respectively. ${ }^{20}$ Other relevant symptoms in our study were chills, headache and running nose. Associated comorbid conditions were also found in the study population. Hypertensive disorder of pregnancy was seen in majority i.e. $15.7 \%$, followed by anaemia (11.4\%), gestational diabetes mellitus $(8.5 \%)$ and hypothyroidism $(7.1 \%)$. Prevalence of hypertension and diabetes were found to be $3.7 \%$ and $4.2 \%$ in the study by Yee et al whereas those in a study done by Richardson et al were $56.6 \%$ and $33.8 \%$ respectively. ${ }^{20,21}$ In current study population of 70, emergency LSCS was done in 29 patients $(41.5 \%)$. LSCS was done for obstetric indications, most common being acute fetal distress. ${ }^{21}$ patients delivered vaginally $(30 \%)$. Thus incidence of LSCS was more than vaginal delivery in our study. Nayak et al conducted a study in which rate of cesarean section was $50 \%$ while Savasi et al reported a rate of $38.6 \% .^{22,23}$ Studies done by Chen et al and $\mathrm{Yu}$ et al reported similar results. ${ }^{24,25}$ Emergency laparotomy was done in 2 patients for ruptured ectopic. Eleven patients, who were remote from term, were managed conservatively according to laid guidelines. Two postLSCS patients who required advanced inotropic support and critical care were shifted to designated COVID care ICU. There was one death during the whole study period. The said patient was COVID positive with provisional diagnosis of severe pre eclampsia with pulmonary edema. Among 50 deliveries in the study population, 10 babies required Neonatal ICU admission (20\%). Low birth weight was seen in $9(18 \%)$. Low APGAR score was found in $6(12 \%)$. There were 2 stillbirths accounting for $4 \%$ of total births in the study population. Thus indicating that COVID-19 infection does not majorly effect the fetal outcome.

\section{CONCLUSION}

The COVID-19 pandemic has been the biggest global public health crisis in this century. The spread and impact of COVID-19 worldwide has been both devastating and unprecedented, and many key questions remain, especially in the context of women's health. This study is a little effort to add to the limited knowledge regarding the ongoing COVID-19 pandemic and pregnancy. Though COVID-19 presents as milder disease in pregnancy, but it may be severe in those with associated comorbidities. ACOG recommends that pregnant individuals have access to COVID-19 vaccines. Pregnant women were not part of the trials for the vaccines currently available under EUA; therefore the safety information available is limited. So further studies regarding COVID infection in pregnancy and efficacy and safety of vaccine is required.

\section{Funding: No funding sources} Conflict of interest: None declared

Ethical approval: The study was approved by the Institutional Ethics Committee

\section{REFERENCES}

1. Human Coronavirus Types. Available at: https://www.cdc.gov/coronavirus/types. Accessed on 20 May 2021.

2. Coronavirus disease (COVID-2019) situation reports 2020. Available at: https://www.who.int/emergencies/diseases/novel-coronavirus-2019/situationreports. Accessed on 20 May 2021.

3. WHO health alert for coronovirus. Available at: https:// www. who. int/emergencies/diseases/ novel coronavirus-2019/ events as -they-happen. Accessed on 20 May 2021.

4. 2019 Novel Coronavirus, Wuhan, China: Symptoms. Available at: https://www.cdc.gov/coronavirus/2019ncov/about/symptoms. Accessed on 20 May 2021.

5. Docherty AB, Harrison EM, Green CA. Features of 16,749 hospitalized UK patients with COVID-19 using the ISARIC WHO clinical characterisation protocol. medRxiv 2020;2020:20076042.

6. Smith V, Seo D, Warty R. Maternal and neonatal outcomes associated with COVID-19 infection: A systematic review. PLOS One. 2020;15(6): $\mathrm{e} 0234187$.

7. Prabhu M, Cagino K, Matthews KC. Pregnancy and postpartum outcomes in a universally tested population for SARS-CoV-2 in New York City: A prospective cohort study. BJOG. 2020;5:45-9.

8. COVID-19: investigation and initial clinical management of possible cases 2020. Available at: https://www.gov.uk/government/publications/wuhan -novel-coronavirus-initialinvestigation-of-possiblecases/investigation-and-initial-clinical-managementof-possible-cases-of wuhan-novel-coronavirus-wncov-infection. Accessed on 5 March 2020.

9. Mor G, Cardenas I. Te immune system in pregnancy: a unique complexity. Am J Reprod Immunol. 2020; 63:425-33.

10. Rasmussen SA, Jamieson DJ, Uyeki TM. Effects of influenza on pregnant women and infants. Am J Obstet Gynecol. 2012;207:S3-8.

11. Qiao J. What are the risks of COVID-19 infection in pregnant women? Lancet. 2020;395:760-2.

12. Favre G, Pomar L, Qi X, Nielsen-Saines K, Musso D, Baud D. Guidelines for pregnant women with suspected SARS-CoV-2 infection. Lancet Infect Dis. 2020;20(6):652-3.

13. Kontou PI, Braliou GG, Dimou NL, Nikolopoulos G, Bagos PG. Antibody Tests in Detecting SARS-CoV2 Infection: A Meta-Analysis. Diagnostics. 2020;10: 319.

14. Chen YH. Pneumonia and pregnancy outcomes: a nationwide population-based study. Am J Obstet Gynecol. 2012;207:e1-7.

15. Wong SF. Pregnancy and perinatal outcomes of women with severe acute respiratory syndrome. Am J Obstet Gynecol.2004;191:292-7.

16. Mehta N, Chen K, Hardy E, Powrie R. Respiratory disease in pregnancy. Best Pract Res Clin Obstet. 2015;29:598-611. 
17. Irani $\mathrm{R}, \mathrm{Xia} \mathrm{Y}$. Renin angiotensin signalling in normal pregnancy and preeclampsia. Semin Nephrol. 2011;31(1):47-58.

18. Vivanti AJ. Retrospective description of pregnant women infected with severe acute respiratory syndrome coronavirus 2, France. Emerg Infect Dis. 2020;26:2069-76.

19. Yan J. Coronavirus disease 2019 in pregnant women: a report based on 116 cases. Am J Obstet Gynecol. 2020;223:e1-14.

20. JeongY, Woorim K, Ji MH, Ha YY, Nari L, Kyung EL. Clinical manifestations and perinatal outcomes of pregnant women with COVID-19: a systematic review and meta analysis. Lancet Infect Dis. 2020;452:521-9.

21. Richardson, S. Presenting characteristics, comorbidities, and outcomes among 5700 patients hospitalized with COVID-19 in the New York city area. JAMA. 2020;323:2052-9.

22. Nayak AH. Impact of the coronavirus infection in pregnancy: a preliminary study of 141 patients. J Obstet Gynaecol. 2020;70:256-61.
23. Savasi VM. Clinical fndings and disease severity in hospitalized pregnant women with coronavirus disease 2019 (COVID- 19). Obstet Gynecol. 2020; 136:252-8.

24. Chen H, Guo J, Wang C. Clinical characteristics and intrauterine vertical transmission potential of COVID-19 infection in nine pregnant women: a retrospective review of medical records. Lancet. 2020;395(10226):809-15.

25. Yu N, Li W, Kang Q. Clinical features and obstetric and neo natal outcomes of pregnant patients with COVID-19 in Wuhan, China: a retrospective, singlecentre, descriptive study. Lancet Infect Dis. 2020; 20(5):559-64.

Cite this article as: Mufti AH, Mukhtar S, Mufti MUH, Wani NJ. Clinical profile and outcome of COVID positive obstetric patients in a tertiary care hospital: a retrospective study. Int J Reprod Contracept Obstet Gynecol 2021;10:3352-6. 